\title{
Chemical Education contra Chemophobia
}

\author{
Alexander Rulev*
}

\begin{abstract}
Where does a negative attitude towards chemistry come from? How does a person begin to fear chemicals and how can one fall in love with chemistry? The problem of chemophobia and the role of education in decreasing its levels are discussed.
\end{abstract}

Keywords: Chemistry · Chemophilia $\cdot$ Chemophobia $\cdot$ Education · Ignorance

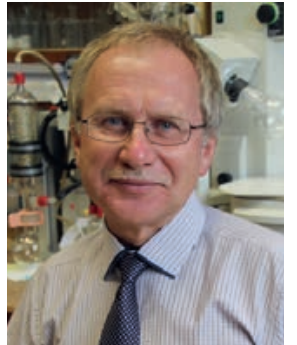

Alexander Rulev obtained a Doctor of Sciences (Chemistry) degree in 2002. He worked as a researcher at the laboratory of organoelement compounds of the Institute of Organic Chemistry, A. E. Favorsky Irkutsk Institute of Chemistry, Russia, headed by academician M. G. Voronkov. In 1995, he was awarded a NATO grant to carry out research at the Laboratoire des Fonctions Azotées et Oxygénées Complexes de l'Université de Rouen (France) with Prof. P. Duhamel and Dr. L. Duhamel. Later he had personal grants from CNRS to do research as a guest scientist at the same Laboratory (1998-2011). He has over 90 papers and two popular science books. In 2016 he was awarded an honorary diploma of the Presidium of the Russian Academy of Sciences for his work on the popularization of science.

\section{Introduction.}

In contrast to other sciences, chemistry probably has had a chance to experience the whole spectrum of relationships between science and human society: from love and admiration to fear and hatred. Indeed, there were times when chemists were considered magicians who could fulfill any desire. They were also mistaken for sorcerers mixing, rubbing, burning or distilling various substances in their gloomy laboratory (chamber of horrors) for fantastic purposes, often quite undesired. ${ }^{[1]}$

A little more than half a century ago it was believed that "chemistry can not only feed but also dress a person, it will bring many convenient, cheap, practical things to one's life", [2] and the famous slogan "Communism is Soviet power plus electrification of the whole country" was supplemented by the phrase: "Plus the chemicalization of the entire national economy."

However, despite providing so many useful things, chemistry has a bad image. Today chemistry is being increasingly anathematized because of the misfortunes it brings and still may bring to the human race. ${ }^{[1]}$

\section{Chemophobia, or how people began to fear chemicals}

It is paradoxical that the wider "chemistry extends its hands into human affairs" and "its successes are visible to us everywhere", ${ }^{[3]}$ fewer and fewer people seem to understand what chemistry is. In our enlightened age, chemophobia as "irrational fear of chemicals" ${ }^{[4]}$ still exists and prospers in the world. One of the well-known examples is the story with the so-called dihydrogen monoxide. In 1997, a fourteen-year-old American student, Nathan Zohner, gathered 43 votes to ban the use of this dangerous chemical, out of 50 peers he asked. Only one student realized that in everyday life dihydrogen monoxide has a more common name - water.

However, the worst thing in this story is that if Nathan Zohner had decided to test adults, he would most likely have had the same result. Indeed, a recent study of the attitude of Europeans towards chemistry has shown that the average European is chemically illiterate. The authors - Professor Michael Siegrist and his colleague Angela Bearth from the Institute for Environmental Decisions, ETH Zurich, Switzerland, evaluated the attitude of Europeans towards chemistry by interviewing residents of eight countries - Austria, Great Britain, Germany, Italy, Poland, France, Switzerland and Sweden (approximately 700 respondents in each country - a total of 5631 people). The picture was depressing (Fig. 1). For example, almost a third of respondents admitted that they are afraid of chemicals, and almost $40 \%$ of them said that in everyday life they try to avoid contact with chemical substances, and would like to live in a world where they do not exist. ${ }^{[5]}$

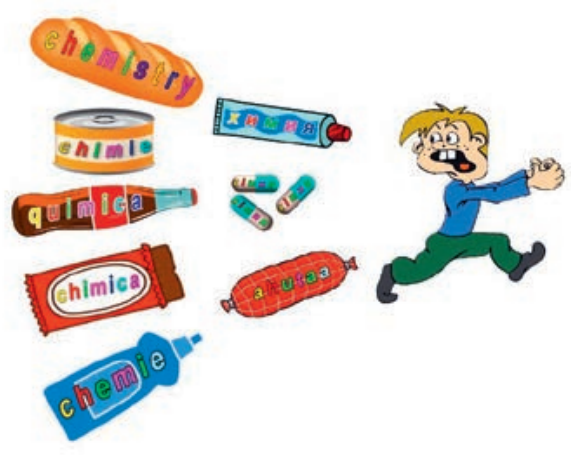

Fig. 1. Chemophobia is everywhere! Alexey Rulev's collage.

When and why did people start to be afraid of chemistry? Today, chemistry is seen as the cause of environmental problems, acid rain, air and ocean pollution. The word 'chemistry' has become synonymous with "something that is harmful or dangerous". This trend was caught by advertisers, doing their best emphasize the absence of such 'chemistry' in the promoted product. Sometimes this borders on the ridiculous.

For example, an advertisement for one drug for weight loss claims that this drug "does not contain any chemical additives and elements and therefore it is very useful for the health of the body". I suppose that the person who takes this bait will need medical 
help when they find out that their 'healthy body' contains more than six dozen chemical elements of the periodic table! In 2002, American scientists Robert Sterner and James Elser calculated the empirical molecular formula for an average person at birth. ${ }^{6]}$ This is, of course, not a true chemical formula: this is only the ratio of elements in our body, consisting of a number of different kinds of organic and mineral compounds. Containing 22 elements, it has the following form:

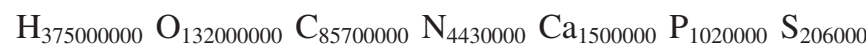
$\mathrm{Na}_{183000} \mathrm{~K}_{177000} \mathrm{Cl}_{127000} \mathrm{Mg}_{40000} \mathrm{Si}_{38600} \mathrm{Fe}_{2680} \mathrm{Zn}_{2110} \mathrm{Cu}_{76} \mathrm{I}_{14} \mathrm{Mn}_{13}$ $\mathrm{F}_{13} \mathrm{Cr}_{7} \mathrm{Se}_{4} \mathrm{Mo}_{3} \mathrm{Co}_{1}$

People suffering from chemophobia believe that natural substances are much more useful and safe than those obtained by chemists in the laboratory. In practice, however, it is not so easy to draw a clear distinction between 'natural' and 'synthetic' products.

Chemophobia often becomes much more dangerous than a chemical! Sometimes it is very difficult to explain to a chemophobe that vitamin $\mathrm{C}$ produced from glucose in great quantity (thousands of tons per year) is the same as natural vitamin $\mathrm{C}$ isolated from rose petals.

It is true that there is the problem of toxic emissions, as well as explosions like the Bhopal disaster - the worst industrial accident in history (India, 1984). It is true that scientists who develop new drugs are doing their best to not repeat the monstrous thalidomide tragedy in the second half of the $20^{\text {th }}$ century. "Imagine if we had stopped science in 1904. Yes, there would have been no nerve gas and no Bhopal, but there would also have been no penicillin. All science is a trade-off", said Nobel Laureate in Chemistry Harold Kroto. ${ }^{[7]}$ According to Roald Hoffmann, Nobel Laureate in Chemistry, "all this is natural, since the molecules created by humans can both heal and harm. Discoveries in chemistry have certainly changed the world we live in. People desire these changes, and at the same time are afraid of them. This is the way chemophobia arises. What to do? I think we should not ignore the instances of harm, for every fear expresses a human contact, and can be turned into an opportunity to teach.'[8] To teach understanding of chemistry, and after that perhaps, just perhaps, stop being afraid of it.

Today, Roald Hoffmann would add "In being capable of both healing and harming you - aren't molecules very much like human beings? Think about it.'[8]

\section{Chemophilia, or how to make a person fall in love with chemistry}

Each of us is a chemist. We are all doing chemistry when we clean the apartment, wash clothes or cook in the kitchen. In fact, the culinary recipe of any gourmet dish is very similar to the method used to perform a chemical experiment in an organic chemistry laboratory. To confirm this point, it is enough to compare the recipe for making homemade ice cream and the usual procedure for, say, the general procedure of organomagnesium synthesis, a common chemical reaction: three grams of magnesium turnings is placed in a flask covered with $20 \mathrm{ml}$ of dry ether. Two milliliters of a solution of bromobenzene in dry ether is added. When the reaction starts (it's called a Grignard reaction), a solution of bromobenzene is added dropwise during 30 minutes. The mixture is stirred continuously, heating at boiling point for the last 15 minutes. Next, the solution of initial ketone is added. The mixture is heated in a boiling water bath for 30 minutes. The heat is then removed and the reaction mixture cooled to room temperature, using an ice water bath, and then decomposed with 5\% hydrochloric acid. The ether layer is separated, washed with a sodium carbonate solution. The solvent is distilled off at atmospheric pressure and the target product, which has solidified after cooling, is dried in air and recrystallized.
The homemade ice cream ingredients needed for the usual recipe are simple: powdered sugar, eggs, milk, 200 grams of chocolate, $150 \mathrm{ml}$ of cream, water. Beat three egg yolks with icing sugar, $300 \mathrm{ml}$ of hot milk is added into this mass, stirring constantly, and heat over low heat until thickened, then cool. In a water bath, melt the chocolate broken into pieces in a water bath, whip the cream. In the cooled mass, put chocolate first, and then cream. Pour into a mold and freeze. Ice cream is ready.

The average person does not even notice that he speaks the same language as professional chemists, and he even uses exactly the same terms! Moreover, the words 'chemistry' or 'chemical' are found in our speech daily. So, in a supermarket, in the section of household chemicals, we choose washing powder or shampoo, for a car we use gasoline produced by a petrochemical company, in a pharmacy we buy drugs manufactured by a branch of chemical industry called pharma, we give things to dry (chemical) cleaners, we hurry to the clinical laboratory to know the results of biochemical tests.

Chemistry is everywhere! "The attempt to do something without chemistry is as naive as attempt to stop the world and get off at a stop," said George Porter, Nobel Laureate in Chemistry. ${ }^{[9]}$ Where does such a negative attitude towards chemistry come from? The answer is obvious and simple: from lack of knowledge. I mean not information, but knowledge! Ignorance breeds fear, and on the contrary, knowledge is a power that can dispel it. Therefore, the knowledge which we receive in secondary school lessons, from scientific-popular magazines and TV educational programs is an important factor in decreasing chemophobia. But where does this ignorance come from in the world today, when everyone is able to find practically any information desired in a few seconds? The answer may seem paradoxical: it comes from an excess of information. Maybe this is quite a startling statement. But in the ocean of information available on the Internet, TV channels, radio, newspapers and magazines, it is sometimes not easy to hear the voice of a scientist or an expert. As the amount of information grows, it is becoming more and more difficult for an average person to select the most important and true information.

Is it possible to solve this problem? There are several ways to do it. One of them was proposed by George Porter. Speaking at the 1985 IUPAC Congress he said: "We should revert to schooling, especially at the most basic level. This should be one of the most important challenges for chemists in the coming decades". ${ }^{\text {9] }}$ This statement remains very relevant today, thirty-five years later.

One of the components of a successful solution of this problem is publishing interesting textbooks and popular science chemistry books. Thus, at the beginning of the 20th century the book 'School of Chemistry' by Nobel Laureate Wilhelm Ostwald was published in Russia (Fig. 2). In the preface to the first edition of this book the editor of the Saint-Petersburg publishing house Vestnik Znaniya (Herald of Knowledge) Wilhelm Beatner wrote: "The book 'School of Chemistry' by the famous Leipzig Prof. Ostwald is a combination of the rare ability to popularize the knowledge for an unprepared reader with an excellent scientific presentation. At the same time, the reader, taking this book, could safely rely on the author to find a picture of the current state of science, rather than an obsolete one, at least ten years ago, abandoned data and ideas that usually fill our official textbooks".

Undoubtedly, the modern textbook must satisfy the same criteria. It is quite obvious that fundamental chemistry concepts will be preserved and the desire for overthrow them should be regarded only as impudence.

The important task of the teacher or professor of chemistry is to bring news to the classroom from scientific laboratories, news which first appeared on the pages of scientific and popular science journals. I have often seen the burning eyes of my lyceum students, particularly, when we studied difficult topics in the ad- 

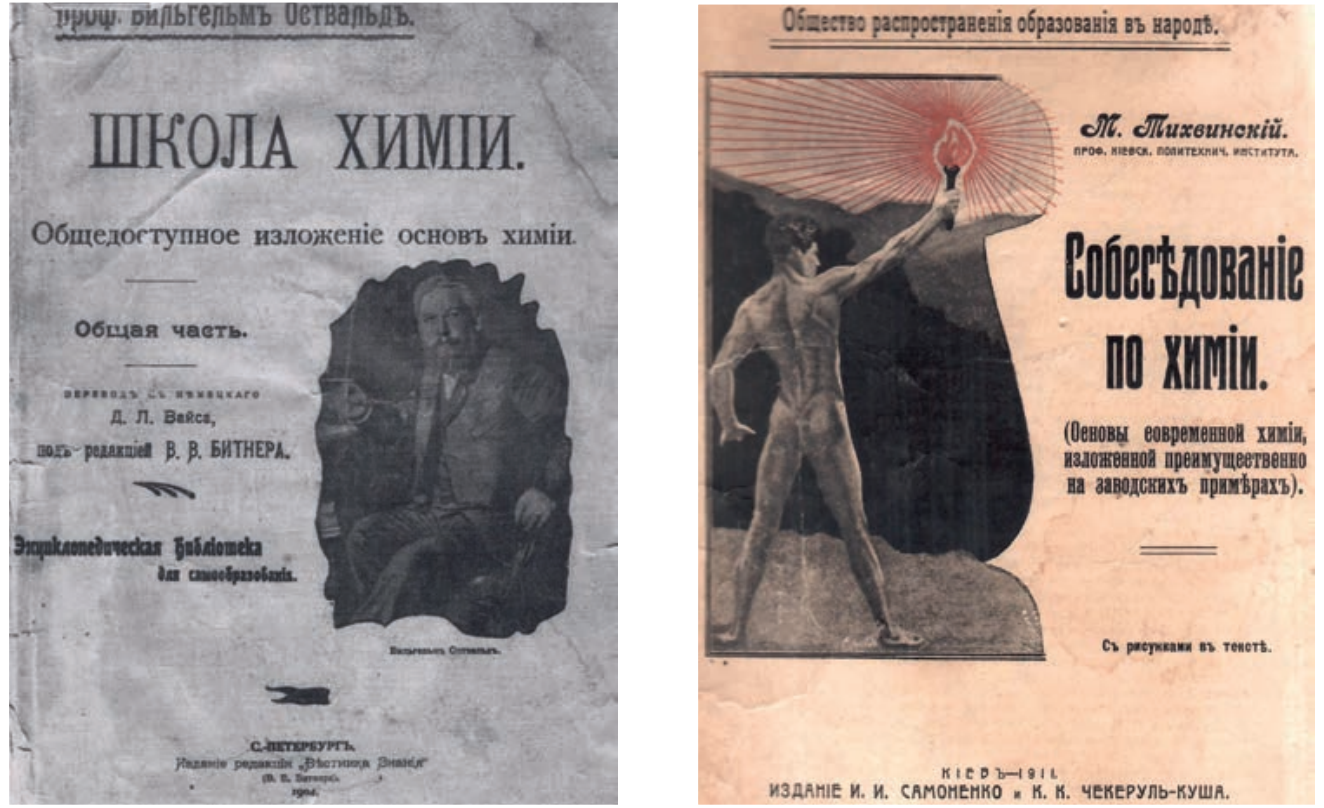

Fig. 2. Textbooks 'School of Chemistry' and 'Interlocutions on Chemistry' for unprepared readers published in Russia at the beginning of 20th century. vanced chemistry course and looked both in the popular science journal and in the university textbook. As a result, they end up seeing that chemistry is beautiful! The highest reward for me was the exclamation of a student: "I understand!" or "I get it!". These 'chemistry admirers' joined the ranks of chemophiliacs (Fig. 3).

Today, there is no doubt that chemicals affect our emotions. In the mid- $20^{\text {th }}$ century, scientists discovered that a state of complete satisfaction and bliss is the result of biochemical processes controlled by the so-called 'hormones of happiness'. For example, lovers produce an increased amount of 'chemicals of happiness', primarily oxytocin, and those who 'glow with happiness' do not experience serotonin or endorphins deficiency. Dopamine is associated with wakefulness; a person having low levels of this hormone risks failing an exam. No, I am not proposing you simply take a pill to replace what only a good teacher may provide, it is not possible!

Chemistry is all around us. The better people know chemistry, the better people know this world. But chemistry is not only around us: it rules the world. At the same time, molecules invisible to our eyes can be effective drugs and powerful poisons. They can turn our world into dust cities and continents and can lead to the

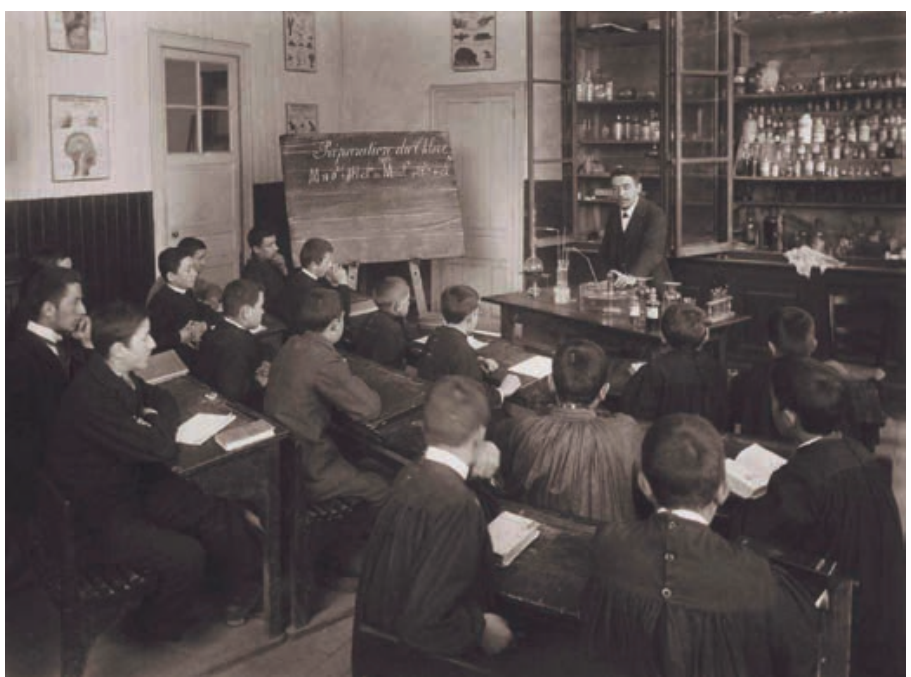

Fig. 3. Lesson of chemistry in the school of La Ferté-Macé (1900) (Reproduced with the permission of the National Museum of Education, Rouen, France). It is impressive with what interest the boys observe the experiment on chlorine preparation! birth of a great civilization. They can control our emotions and push people to monstrous crime or serendipitous discoveries. ${ }^{[10]}$ They can transform our planet into blooming garden or a lifeless desert.

When the most inveterate chemophobe admits that chemistry is in our life, that chemistry is everywhere - around and inside us, perhaps he will get to know this science more closely, and when he recognizes it, he will no longer fear it and, perhaps (why not?), fall in love with it. As a result, the family of chemophiliacs will grow.

\section{Acknowledgements}

I would like to express warm feelings and gratitude to my wife, Tamara, a high school chemistry teacher, for her help and support over the several unforgettable years of my pedagogical activity in Gymnasium and University Lyceum. I would like to thank Professor Roald Hoffmann, Nobel laureate in Chemistry, for his interest in this article. I appreciate each comment and suggestion that he made.

Received: June 8, 2020

[1] O. Krätz. Angew. Chem. Int. Ed. 2004, 43, 1770, https://doi.org/10.1002/anie.200330064.

[2] From the speech of N. Khrushchev at the Plenum of the Central Committee of the CPSU on December 9, 1963.

[3] M. V. Lomonosov, 'Full composition of writings' V. 2., Proc. Phys. Chem. Moscow, Publisher House of the Academy of Sciences of the USSR, 1951.

[4] J. H. Duffus, M. Nordberg, D. M. Templeton. Pure Appl. Chem. 2007, 79, 1153, https://doi.org/10.1351/pac200779071153.

[5] M. Siegrist, A. Bearth. Nature Chem. 2019, 11, 1071, https://doi.org/10.1038/s41557-019-0377-8.

[6] R. W. Sterner, J. J. Elser, Ecological Stoichiometry: the Biology of Elements from Molecules to the Biosphere', Princeton University Press, 2002.

[7] www.brainyquote.com/authors/harry-kroto-quotes.

[8] R. Hoffmann. Private communication.

[9] M. Freemantle, 'Chemistry in action', MacMillan Press, 1987, p.249.

[10] A. Yu. Rulev. New J. Chem. 2017, 41, 4262 , https://doi.org/10.1039/c7nj00182g.

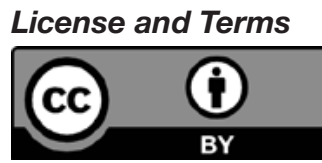

This is an Open Access article under the terms of the Creative Commons Attribution License CC BY 4.0. The material may not be used for commercial purposes.

The license is subject to the CHIMIA terms and conditions: (http:// chimia.ch/component/sppagebuilder/?view=page $\& i d=12$ ).

The definitive version of this article is the electronic one that can be found at https://doi.org/10.2533/chimia.2021.98 